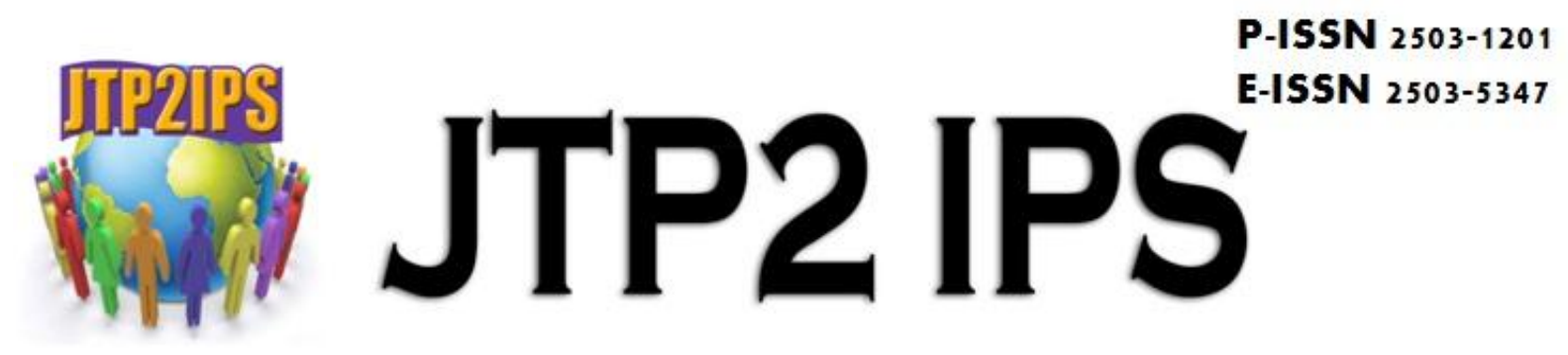

\title{
PENGEMBANGAN PEMBELAJARAN BLENDED LEARNING PADA GENERASI Z
}

\author{
Agus Purnomo', Nurul Ratnawati ${ }^{2}$, Nevy Farista Aristin ${ }^{3}$
}

\begin{abstract}
Abstrak
Setiap generasi mempunyai kepercayaan, nilai, budaya, perspektif, kegemaran, dan kemahiran yang berbeda terhadap kehidupan dan pekerjaan. Generasi yang lahir pada awal tahun 2000an saat perkembangan teknologi sedemikian pesatnya disebut dengan generasi $z$ atau net generation. Karakter dari generasi ini sangat peka terhadap teknologi dan komunikasi, artinya mereka memiliki keunggulan dalam bidang informasi dan perkembangan pengetahuan. Sementara para pendidiknya yang lahir pada era sebelumnya masih belum terbiasa dengan hal itu sehingga seringkali pendidik mengaku "gaptek" (gagap teknologi). Untuk menyikapi hal tersebut perlu ada inovasi baru dalam proses belajar mengajar sehingga sesuai dengan karakter tersebut. Mengkombinasikan pembelajaran konvensional dengan media komunikasi seperti whatsapp dan google drive merupakan salah satu solusi mudah pembelajaran IPS pada generasi-z. Peserta didik yang terbiasa berkomunikasi menggunakan jejaring sosial dapat mengakses materi dan rencana pembelajaran yang sudah disusun dengan terstruktur setiap pertemuan. Sehingga mereka dapat membaca atau menyiapkan pertanyaan sebelum pembelajaran dimulai. Proporsi penggunaan e-learning pada pembelajaran ini mencapai 35\% sehingga bisa disimpulkan sebagai pembelajaran blended learning. Pembelajaran ini berdiri di atas infrastruktur teknologi informasi dan bisa dilakukan kapanpun dan dimanapun. Jadi pembelajaran blended learning memiliki karakteristik yang terbuka (open), fleksibel, dan dapat terjadi dimana saja.
\end{abstract}

Kata kunci: Generasi Z dan blended learning

\begin{abstract}
.
Every generation has beliefs, values, cultures, perspectives, interests, and different skills for life and work. The generation born in the early 2000s when the rapid development of such technology referred to as generation-z or net generation. Characters of this generation is very sensitive to technology and communication, meaning they have an advantage in the field of information and knowledge development. While the educators who were born in an earlier era are still not familiar with it so that educators often claimed to be "clueless" (stuttering technology). To address this need no new innovations in the learning process so that it complies with these characters. Combines conventional learning with communication media such as whatsapp and google drive is one easy solution social studies lesson on the generation-z. Learners who are accustomed to communicate using social networks can access the material and lesson plans that have been prepared with structured each meeting. So that they can read or prepare questions before the learning begins. The proportion of the use of e-learning in this study reached $35 \%$ so that it can be summed up as learning blended learning. This learning to stand on its information technology infrastructure and can be done anytime and anywhere. So learning blended learning has characteristics that are open, flexible, and can occur anywhere.
\end{abstract}

Keywords: Generation Z and blended learning

\footnotetext{
${ }^{1}$ Prodi Pendidikan IPS Fakultas Ilmu Sosial - Universitas Negeri Malang, purnomo.agus88@gmail.com

${ }^{2}$ Prodi Pendidikan IPS Fakultas Ilmu Sosial - Universitas Negeri Malang, noerulmahfida@gmail.com

${ }^{3}$ Prodi Pendidikan Geografi - Universitas Lambungmangkurat, nevyfarista@gmail.com
} 


\section{PENDAHULUAN}

Kiprah pendidikan senantiasa hidup dalam suatu dunia yang terus berubah seiring dengan kemajuan teknologi informasi dan perubahan demografi. Jika dunia pendidikan tidak menyelaraskan diri dengan perkembangan jaman tersebut, pendidikan akan menjadi usang dan tidak selaras dengan kemajuan di milenium kedua ini. Generasi muda saat ini, yang disebut juga Generasi $\mathrm{Z}$ atau Net Generation, mempunyai karakteristik yang membuat mereka berbeda dengan generasi terdahulu. Jika dunia pendidikan tidak membuat upaya untuk memetakan profil khas pembelajar ini dan merancang pola pembelajaran yang sesuai, akan terbentuk kesenjangan antara keduanya.

Pendidik di zaman informasi ini mempunyai kecenderungan gaya belajar aktif, sequential, sensing, dan visual (Felder dan Soloman, 1993). Pendidik aktif mudah belajar dengan melakukan sendiri apa yang sedang dipelajari. Maka, mata kuliah yang terlalu banyak bersifat ceramah dan komunikasi satu arah serta terpusat kepada dosen (teacher-centered) tidak akan cocok dengan mereka. Sebaliknya, pembelajaran yang membuat mereka menerapkan teori dan melakukan sendiri apa yang sedang dipelajari akan dengan mudah menarik minat dan pada gilirannya kemampuan belajar mereka.

Mereka yang bergaya belajar sequential mudah menyerap materi yang diberikan secara runtut, berurutan secara logis, dan dengan jelas terkait antara satu dengan lainnya. Mereka dengan gaya belajar sensing cenderung menyukai fakta, menyukai hal-hal yang penerapan praktisnya jelas, mengharapkan relevansi dengan dunia sehari-hari, dan kurang suka teori abstrak dan tes yang materinya belum dibahas tuntas di kelas. Akhirnya, mereka dengan gaya belajar visual akan terbantu dengan bagan, skema, dan diagram alir dari rangkaian teori yang sedang mereka kupas.

Keempat gaya belajar ini selaras dengan kecenderungan generasi $\mathrm{Z}$ yang kehidupannya sarat dengan interaksi lewat ber-bagai media virtual seperti ponsel, Blackberry, dan Internet. Kesimpulannya, sudah saatnya praktek pendidikan mengakomodasi kecenderungan ini melalui kombinasi yang efektif antara pembelajaran teori dengan eksplorasi dunia maya melalui berbagai piranti teknologi informasi tersebut.

Keunikan generasi Z, cenderung melakukan gaya multitasking, yaitu melakukan beberapa pekerjaan bersamaan. Mereka senang dengan persoalan-persoalan yang membutuhkan pengambilan keputusan yang cepat. Andalannya adalah internet yang merupakan sumber melimpah dalam pendukung pengambilan keputusan.

Membelajarkan anak generasi $\mathrm{Z}$ akan menjadi hal sulit jika pendidik masih menerapkan gaya masa lalu, seperti menggunakan metode Duduk Dengar Catat Hapal (DDCH). Kini bukan zamannya lagi anak duduk menghabiskan waktu dengan mendengarkan, merangkum dan menuliskan PR di buku tulis. Seiring perkembangan zaman, pendidik harus meninggalkan cara lama agar sukses membimbing generasi $\mathrm{Z}$ menghadapi masa depan. Sangat diperlukan inovasi dalam mengajar anak generasi Z, karena mereka mempunyai konsep berpikir yang berbeda. Lingkungan generasi $\mathrm{Z}$ bukan hanya alam nyata, tetapi juga alam maya.

Seiring dengan berjalannya waktu, kebutuhan manusia semakin berkembang dan bertambah. Penemuan teknologi-teknologi baru menjadi salah satu faktor penunjang bertambahnya kebutuhan baru dalam segala bidang, termasuk pada bidang pendidikan. Inovasiinovasi baru lahir seiring dengan berkembangnya teknologi dan kebutuhan pendidik dan terutama peserta didik. Hidup di zaman yang katanya zamannya generasi $\mathrm{Z}$ di mana generasi ini terbiasa mendapatkan informasi beragam dalam waktu yang sangat singkat, hanya dengan "pencet tombol ini, maka lihat apa yang akan terjadi” (Musyarofah, 2014).

Mobilitas manusia yang semakin padat dan lahirnya teknologi-teknologi baru, menjadi latar belakang lahirnya model pembelajaran blended learning sebagai inovasi baru dalam menjawab tantangan zaman. Blended learning adalah istilah dari pencampuran antara model pembelajaran konvensional yang biasa dilakukan secara face to face dengan model pembelajaran berbasis internet yang biasa dikenal dengan istilah e-learning (Uno, 2011).

Model pembelajaran ini merupakan cara belajar yang murah dan efektif (Suyono, 2011). Model pembelajaran ini bisa diterapkan kepada siapa saja, terutama untuk mereka yang mempunyai mobilitas tinggi dan sulit untuk terus bertatap muka secara langsung dengan pendidik atau dosen. Alasan lain adalah sebagai sarana belajar bersama untuk mereka yang merasa membutuhkan materi tambahan. Mereka kurang 
puas dengan pembelajaran konvensional di kelas, karena dengan blended learning mereka bisa dengan mudah men-dapatkan materi-materi baru bahkan lebih up to date dari berbagai sumber bahkan pakar dari seluruh belahan dunia. Generasi Z sudah sangat dimanjakan sekali dengan berbagai kemudahan-kemudahan yang ditawarkan. Tidak zamannya lagi kita harus berdiam diri menunggu intruksi dari pendidik saja di sekolah. Dari kenyataan yang telah dipaparkan di atas maka fokus kajian dalam penelitian ini adalah, "Bagaimanakah formula penerapan Blended Learning pada Generasi Z?"

\section{METODE PENELITIAN}

Perancangan formulasi Blended Learning menggunakan Model ADDIE yang merupakan salah satu model desain pembelajaran yang memperlihatkan tahapan-tahapan desain yang sederhana dan mudah dipelajari adalah model ADDIE (Analysis-Design-Develop-ImplementEva-luate). ADDIE muncul pada tahun 1990-an yang dikembangkan oleh Reiser dan Mollenda. Salah satu fungsinya yaitu menjadi pedoman dalam membangun perangkat yang efektif, dinamis dan mendukung pembelajaran. Model ini menggunakan 5 tahap pengembangan (Sukenda dkk. 2013) yakni:

1) Analysis

Analisis merupakan tahap pertama yang harus dilakukan oleh seorang pengembang pembelajaran. Kaye Shelton dan George Saltsman (2007) menyatakan ada tiga segmen yang harus dianalisis yaitu peserta didik, pembelajaran, serta media untuk menyampaikan bahan ajarnya. Langkah-langkah dalam tahapan analisis ini setidaknya adalah: menganalisis peserta didik; menentukan materi ajar; menentukan standar kompetensi (goal) yang akan dicapai; dan menentukan media yang akan digunakan.

2) Design

Pendesainan dilakukan berdasarkan apa yang telah dirumuskan dalam tahapan analisis. Tahapan desain adalah analog dengan pembuatan silabus. Dalam sila-bus tersebut harus memuat informasi kontak, tujuan-tujuan pembelajaran, persyaratan kehadiran, kebijakan keterlambatan pekerjaan, jadwal pembelajaran, pengarahan, alat bantu komunikasi, kebijakan teknologi, serta desain antar muka untuk pembelajaran. Langkah-langkah dalam tahapan ini adalah membuat silabus yang di dalamnya termasuk: memilih standar kompetensi (goal) yang telah dibuat dalam tahapan analisis; menentukan kompetensi dasar (objektif); menentukan indikator keberhasilan; memilih bentuk penilaian; menentukan sumber atau bahan-bahan belajar; menerapkan strategi pembelajaran; membuat storyboard; mendesain antar muka;

\section{3) Development}

Tahapan ini merupakan tahapan produksi dimana segala sesuatu yang telah dibuat dalam tahapan desain menjadi nyata. Langkah-langkah dalam tahapan ini diantaranya adalah: membuat objek-objek belajar (learning objects) seperti dokumen teks, animasi, gambar, video dan sebagainya; membuat dokumen-dokumen tambahan yang mendukung.

4) Implementation

Pada tahapan ini sistem pembelajaran sudah siap untuk digunakan oleh peserta didik. Kegiatan yang dilakukan dalam tahapan ini adalah mempersiapkan dan memasarkannya ke target peserta didik.

\section{5) Evaluation}

Evaluasi dapat dilakukan dalam dua bentuk evaluasi yaitu formatif dan sumatif. Evaluasi formatif dilakukan selama dan di antara tahapan-tahapan tersebut. Tujuan dari evaluasi ini adalah untuk memperbaiki sistem pembelajaran yang dibuat sebelum versi terakhir diterapkan. Evaluasi sumatif dilakukan setelah versi terakhir diterapkan dan bertujuan untuk menilai keefektifan pembelajaran secara keseluruhan. Pertanyaan-pertanyaan yang dapat diajukan dalam tahapan evaluasi adalah: Apakah tujuan belajar tercapai oleh peserta didik?; Bagaimana perasaan peserta didik selama proses belajar? suka, atau tidak suka; Adakah elemen belajar yang bekerja dengan baik atau tidak baik?; Apa yang harus ditingkatkan?; Apakah informasi dan atau pesan yang disampaikan cukup jelas dan mudah untuk dimengerti?; Apakah pembelajaran menarik, penting, dan memotivasi?

Pembelajaran ini dikembangkan dan diujicobakan pada tiga tempat yang berbeda, yaitu: Prodi Pendidikan Ilmu Pengetahuan Sosial - Universitas Negeri Malang, Prodi Pendidikan Geografi - Universitas Lambungmangkurat, dan Prodi Pendidikan Geografi - Universitas Kanjuruhan Malang. Dan juga diterapkan pada 9 mata 
kuliah yang berbeda. Diharapkan dengan variasi yang cukup banyak akan didapatkan hasil yang lebih bagus dalam mendeskripsikan pengembangan pembelajaran ini.

\section{PEMBAHASAN}

Analisis sebagai tahap pertama terdiri dari 2 hal, yaitu analisis kinerja dan analisis kebutuhan peserta didik. Analisis kinerja ditujukan untuk mengidentifikasi masalah dalam pembelajaran. Masalah yang didapatkan adalah banyak peserta didik yang kurang fokus selama perkuliahan yang dikarenakan faktor-faktor kelelahan dan kebosanan/kejenuhan. Dari beberapa peserta didik yang didapatkan hasil yang menarik. Mereka mengaku bahwa materi yang dijelaskan sama sekali asing bagi mereka sehingga jika cara penyampaiannya hanya menggunakan ceramah maka membuat mereka cepat bosan. Mereka mengaku kelelahan setelah mengerjakan tugas atau setelah perkuliahan yang tanpa jeda sehingga mereka kekurangan tenaga untuk konsentrasi pada perkuliahan meskipun niat mereka untuk ikut perkuliahan tinggi, hal ini terjadi pada perkuliahan pada jam sore.
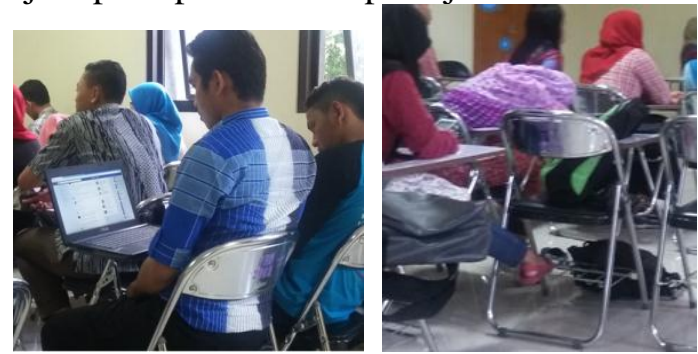

Gambar. 1 kiri. peserta didik yang sedang membuka akun jejaring sosial ketika perkuliahan. Gambar. 2 kanan peserta didik yang kelelahan saat perkuliahan berlangsung.

Analisis kebutuhan peserta didik ditujukan untuk mengidentifikasi solusi yang sekiranya dapat digunakan untuk mengatasi masalah pembelajaran yang telah diungkapkan tadi. Beberapa solusi antara lain menggunakan media komunikasi dalam memberikan materi sehingga mereka mempunyai gambaran sebelum mengikuti proses perkuliahan, karena Silabus yang telah dibagikan saja tidaklah cukup. Media komunikasi yang digunakan harus media yang familiar bagi peserta didik agar mudah penggunaannya, berdasarkan hal itu maka media yang dipilih adalah aplikasi smart phone Whatsapp dan akun google drive untuk berbagi (share) materi pembelajaran. Kedua media komunikasi itu diharapkan mampu untuk membantu peserta didik dalam mengakses bahan belajar mereka, dan membantu pendidik untuk menyebarluaskan materi ajarnya dengan efisien dan efektif.

Tahap berikutnya adalah desain pembelajaran. Desain tersebut bertujuan untuk merancang pengalaman belajar yang perlu dimiliki peserta didik selama mengikuti perkuliahan. Pengalaman belajar mencakup deskripsi media belajar, bahan ajar, hingga evaluasi yang digunakan. Indikator keberhasilan dari proses pembelajaran adalah tercapainya tujuan belajar yang ada pada rencana yang sudah dibuat dan disepakati pada awal perkuliahan. Hasil dari desain ini adalah story board perkuliahan yang kemudian dikembangkan menjadi pembelajaran blended laerning.

Rencana pengembangannya diawali dengan membuat kesepakatan dengan peserta didik agar pembelajaran sesuai dengan kebutuhannya. Setelah melakukan proses diskusi didapatkan hasil bahwa materi kegiatan belajar diunggah pada akun google drive setiap awal minggu. Peserta didik dapat mengaksesnya baik dari komputer ataupun dari smart phone yang mereka miliki di rumah atau di tempat kost. Keluesan dan fleksibilitas ini yang menjadi unggulan dari blended learning.

Agar memudahkan dalam penggunaannya maka isi konten disampaikan diawal perkuliahan dan bagaimana cara penggunaan dari akun tersebut. isi dari konten tersebut terdiri dari 6 folder mata kuliah 1 folder tempat untuk berbagi dengan nama sharing dan 1 file peraturan yang harus dibaca oleh seluruh pengguna. Dalam konten mata kuliah tiap-tiap pertemuan disajikan dalam folder-folder pertemuan. Tiap-tiap pertemuan memiliki folder tersendiri sehingga peserta didik mudah dalam mengakses materi yang diinginkan.

Tahap berikutnya adalah penerapan langsung pada peserta didik. Pada tahap uji coba ini blended learning menggunakan aplikasi google drive dan whatsapp telah berjalan 13 pertemuan. Keseluruhan pertemuan telah berhasil dilaksanakan sesuai dengan rencana yang telah disepakati pada awal perkuliahan. Adapun masukan dalam pembelajaran ini adalah keterbatasan quota yang dimiliki oleh peserta didik. Kondisi ini mengakibatkan pembelajaran yang kurang efisien. Karena mereka hanya dapat 
belajar di area kampus yang memiliki koneksi internet stabil. Padahal pada esensinya blended learning bertujuan agar peserta didik dapat belajar dimana saja dan kapan saja tanpa perlu menunggu perkuliahan di dalam kelas.

Terlepas dari kondisi tersebut, peserta didik merasa nyaman dan lebih mudah mengakses bahan atau materi perkuliahan sehingga mereka memiliki persiapan yang lebih baik selama proses perkuliahan. Penggunaan media ini juga membuat suatu kondisi yang saling terbuka antara pendidik dan peserta didiknya. Karena bahan dan materi pembelajaran yang diunggah oleh pendidik untuk perkuliahan dapat diakses dengan bebas oleh peserta didik. Tidak hanya itu, akses yang sama juga diberikan kepada peserta didik membuat kedua pihak ini memiliki hak yang sama dalam menggunakan akun tersebut.

Tepat setelah pertemuan ke-7 beberapa hasil dari tulisan ini sudah disajikan dalam beberapa forum ilmiah untuk mendapatkan saran dan masukan yaitu, memasukan gedget yang selama ini menjadi salah satu permasalahan di dalam kelas merupakan sebuah solusi yang kreatif sehingga peserta didik mampu melihat manfaat positif dari barang pribadinya. Dan blended learning yang selama ini menjadi alasan bagi seorang pendidik untuk dapat tidak masuk kelas kini telah menjadi sebuah media komunikasi antara pendidik dan peserta didik dalam sebuah pembelajaran yang fleksibel, efektif dan efisien. Dalam proses belajar mengajar, salah satu unsur yang sangat penting adalah media pembelajaran. Media pembelajaran memiliki fungsi utama sebagai alat bantu mengajar yang turut mempengaruhi iklim, kondisi, dan lingkungan belajar yang ditata dan dirancang oleh pendidik. Hal tersebut sesuai dengan pendapat Gagne, Briggs, and Wager 1992 yaitu ..."instructional media are the physical means by which an instructional message is communicated".

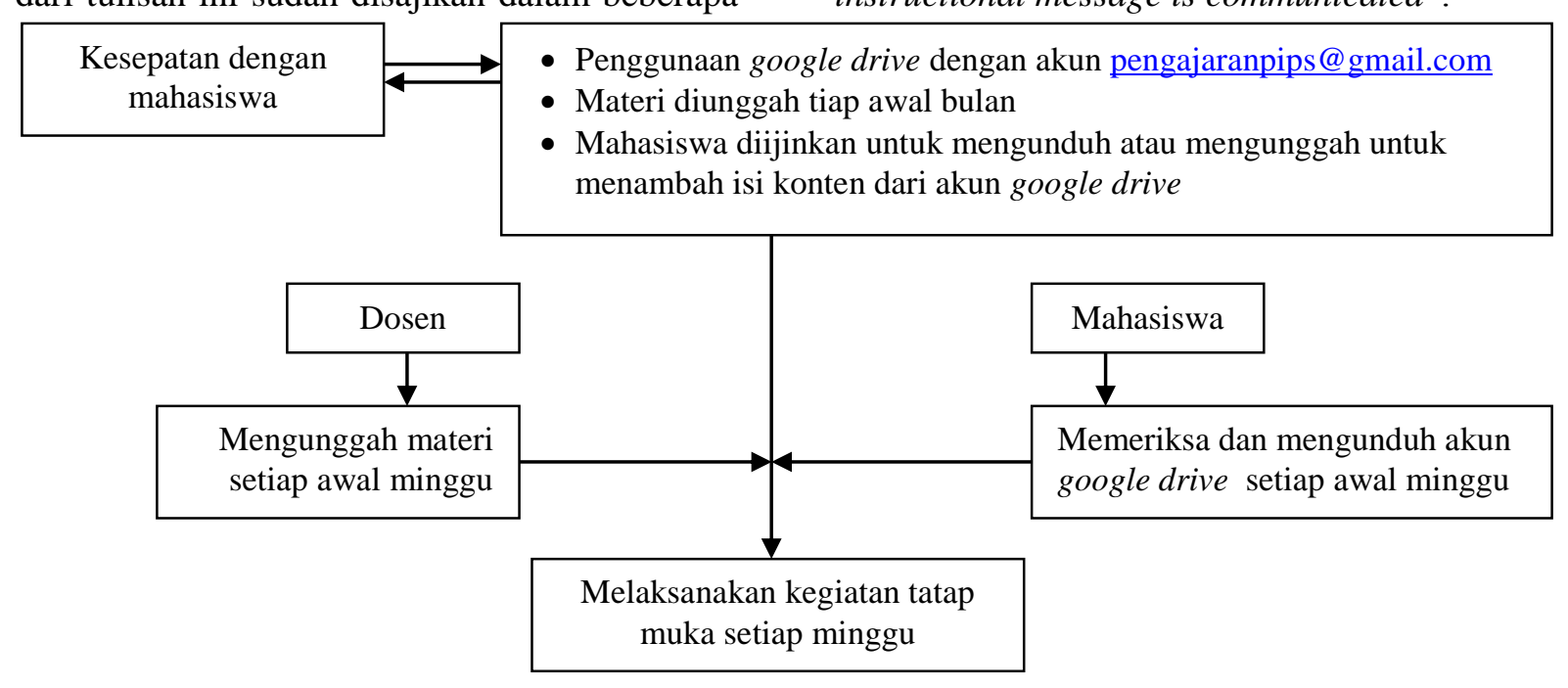

Gambar 3. Desain pembelajaran Blended Learning

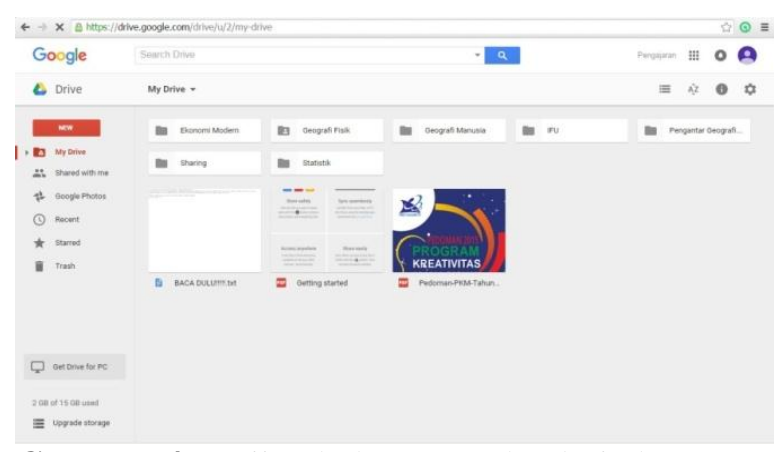

Gambar 4. Sajian halaman muka dari akun pendidikanpips@gmail.com, terdapat 6 folder mata kuliah dan 1 folder sharing serta 1 file peraturan pengguna

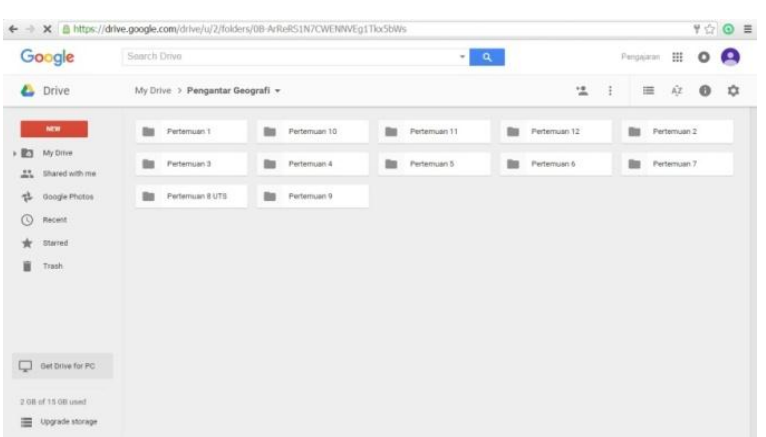

Gambar 5. Sajian salah satu halaman di folder mata kuliah yang berisi bahan tiap-tiap pertemuan 
Hingga 13 kali pertemuan pembelajaran ini masih dalam tahap pengembangan dan uji coba. Dari hasil evaluasi sementara yang dilakukan pada beberapa mata kuliah didapatkan hasil sebagai berikut. (1) mata kuliah Pengantar Geografi, dari peserta didik yang berjumlah 36 , 35 diantaranya mendapatkan nilai rata-rata di atas 78 , dan 15 peserta didik tercatat selalu aktif dalam setiap perkuliahan. (2) mata kuliah Statistika, dari peserta didik yang berjumlah 35 , 29 diantaranya mendapatkan nilai rata-rata di atas 75 , dan 11 peserta didik tercatat selalu aktif dalam setiap perkuliahan. Dan (3) mata kuliah Intrepertasi Foto Udara, dari peserta didik yang berjumlah 30, 29 diantaranya mendapatkan nilai rata-rata di atas 80 , dan tercatat 10 peserta didik selalu aktif dalam setiap perkuliahan.

Berdasarkan dari hasil tersebut maka dapat dirata-rata peserta didik hampir seluruhnya dapat mengikuti proses pembelajaran dengan baik yang ditunjukkan dari nilai dan keaktifan di dalam kelas. Pada mata kuliah Pengantar Geografi 99\% mendapatkan nilai yang baik, mata kuliah Statistika $82 \%$ mendapatkan nilai yang baik, dan pada mata kuliah Intrepertasi Foto Udara 99\% mendapatkan nilai yang baik.

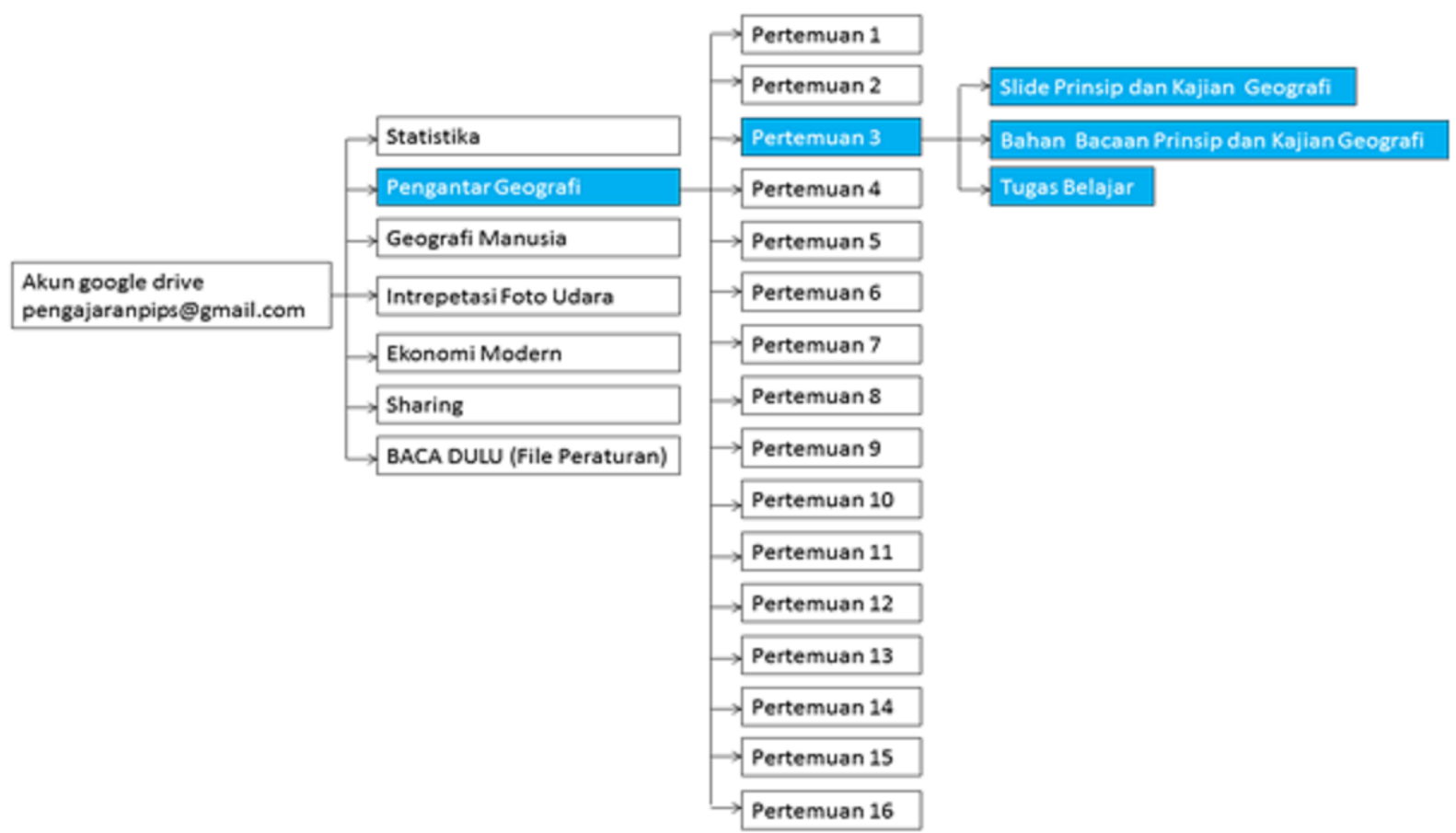

Gambar 7. Story Board salah satu mata kuliah (Pengantar Geografi) pada pertemuan ke-3

\section{KESIMPULAN}

Penyusunan pembelajaran blended learning pada 3 perguruan tinggi menggunakan model ADDIE yang terdiri dari 5 tahapan sejauh ini sudah tergolong baik. Tahap yang paling penting dalam pengembangannya adalah pada pada tahap pertama, analisis. Tahap ini mengidentifikasi masalah yang mungkin muncul dalam proses pembelajaran dan asumsi solusi yang ada. Jika pada tahap ini sudah salah dalam mengidentifikasi maka kebutuhan belajar yang diperlukan oleh peserta didik tidak akan dapat dipenuhi oleh pendidik. Karakter generasi Z yang menyukai hal instan memang sangat cocok jika menggunakan pembelajaran ini karena sifatnya yang fleksibel, efektif, dan efisien. Tetapi perlu digaris bawahi bahwa pengetahuan penggunaan teknologi informasi mereka sangat berbeda-beda. Kebanyakan dari mereka hanya sebatas pada pengguna gedget, bukan pengguna teknologi.

\section{DAFTAR PUSTAKA}

[1] Felder, R.M., and Soloman, B.A. 1993. Learning styles and strategies.

[2] Gagne, R.M, Briggs, L.J and Wager, W.W. 1992. Principles of instructional design. Fort Worth, TX: Harcourt Brace Jovanovich, Publishers. 
Vol.1 No.1 April 2016

P ISSN 2503 - 1201 \& E ISSN 2503 - 5347

[3] Kaye Shelton and George Saltsman. 2007. Using the ADDIE Model for Teaching Online. IDEA GRUP PUBLISHING. Paper dipublikasikan dalam International Journal of Information and Comunication Technology Education.

[4] Kemendikbud. 2013. Pedoman Umum Pembelajaran - Lampiran IV - Peraturan Menteri Pendidikan Dan Kebudayaan Republik Indonesia Nomor 81a Tahun 2013 Tentang Implementasi Kurikulum

[5] Musyarofah, Umi Wahidatun. 2014. Pendidikan di Indonesia Gagal Move On. Paper Pengembangan Karya Ilmiah, Oktober 2014.

[6] Sukendah. 2013. Pengembangan Aplikasi Multimedia Pengenalan Pemanasan Global dan Solusinya Menggunakan Pendekatan ADDIE. Makalah dipresentasikan di Seminar Nasional Sistem Informasi Indonesia 2-4 Desember 2013.

[7] Suyono \& Hariyanto. 2011. Belajar dan Pembelajaran. Bandung: Rosda.

[8] Uno, B. Hamzah. 2011. Model Pembelajaran. Jakarta: Bumi Aksara. 


\section{MITRA BESTRARI}

\begin{tabular}{r|l} 
Paulus Wirutomo & Universitas Indonesia \\
Udin Saripudin Winataputra & Universitas Terbuka \\
Trisno Martono & Universitas Negeri Jakarta \\
Eko Handoyo & Universitas Seebelas Maret \\
Taat Wulandari & Universitas Negeri Semarang \\
Nasution & Universitas Negeri Surabaya \\
Hariyono & Universitas Negeri Malang \\
Ach Fatchan & Universitas Negeri Malang \\
Sumarmi & Universitas Negeri Malang
\end{tabular}

